\title{
Research on Linear Programming Algorithm for Mathematical Model of Agricultural Machinery Allocation
}

\author{
Xiaoling Zhou, Basic Course Department, Guangzhou Railway Polytechnic, China \\ Amit Sharma, Department of Computer Science and Engineering, Chitkara University, Chandigarh, India \\ Vandana Mohindru, College of Engineering, Chandigarh Group of Colleges, India \\ (iD https://orcid.org/0000-0002-2994-9637
}

\begin{abstract}
The objective of this paper is to study the linear programming algorithm of the mathematical model of agricultural machinery allocation when there are many farmland projects and cross operations. In this paper, combined with the mechanization process of crops in XPCC, the linear programming algorithm of mathematical model was used to establish the allocation scheme of different scales. All equations were solved and analyzed, and the allocation schemes of different planting scales were compared. It is also observed that through the interactive conflicts in between multiple objectives a solution vector can be analyzed. The results show that the activity cost of Scheme 5 was the lowest, only 1,260 yuan per mu, which was the best way to equip agricultural machinery. The results present that it is of great significance to optimize the configuration of agricultural machinery. The experimental results present that the portion of water which is reused in comparison with the total water is gradually increasing which leads to the overall reduction in water consumption.
\end{abstract}

\section{KEYWORDS}

Agricultural Machinery Equipment, Linear Programming, Model

\section{INTRODUCTION}

Agricultural mechanization as an important part of the whole management, whether the agricultural machinery is complete or not is directly related to the economic benefits of China's mechanization. Therefore, Tiechuang et al. (2018) only by setting up agricultural machinery reasonably and reducing the cost input as much as possible, can we realize the maximization of economic benefits. At present, there are many calculation methods about agricultural machinery. With the development of science and technology in China, the related engineering technology is widely used in the field of agricultural machinery. The advent of the Internet era has promoted the application of computer in the mathematical planning model of agricultural machinery. Lang et al. (2018) in order to improve the economic benefits of agricultural machinery allocation, the working time and workload of the

DOI: 10.4018/IJAEIS.2021070101

This article published as an Open Access article distributed under the terms of the Creative Commons Attribution License (http://creativecommons.org/licenses/by4.0/) which permits unrestricted use, distribution, and production in any medium, provided the author of the original work and original publication source are properly credited. 
whole project stage should be considered in the mathematical programming model of agricultural machinery allocation.

The accessibility of resources in the region plays a significant role in the organization of the farm. Crop type, crop density, crop distribution, crop diversity, and crop combinations are necessary decisions for adjustment during growth. An analysis of crop distribution and other management methods is proposed for the statistical model. Planning of farms and its management are related to many controlled factors and some of factors which are uncontrollable. To gain understanding from these boundaries of farms Martin et al. (2015) creates a farm model that combines yield in a multi-time space. The approach of Linear Programming is used for determining the practicability of decision-making.

In developing season farmers need to dispense their fields under an alternate collection of crops relying upon past seasons, crop yield and cost of market. Likewise, they need to anticipate the crop production of the coming season as well. Such a choice is very testing and basic. On the other hand, to help the farmers and to allot the resource optimally the decision support approach is discussed by Prišenk et al. (2014). The model depends on two ideas; crop allocation and decision of crop rotation. The crop allocation and its planning are the foundation decision of crop management framework. Such choices concentrate all the complexities engaged with a framework and choices accessible at the farm level due to their contribution at various phases of crop production.

Therefore, planning of crop is critically important step in crop production and thereby presents a huge impact on farm income. The crop system framework must provide a connection among the farm parameters in this regard, sustaining all the conflicting objectives. Most of the models deal with plant system selection which is represented by crop selection or includes rotation of crop as a perception. A combined farm model was developed by Lanfranchi et al. (2015) for the purpose of increasing farm income. It is challenging to achieve the potential for such a dynamic decision-making process due to the huge amount of constraints involved and their difficult connections or interfaces. In the farming scheme the choices of the crop system are very important. Therefore, a knowledge-based method is implemented to create a combined farm plan. Such a combined state of the farm delivers insight into determining the shortage of constraints to adjust according to the availability and accessibility of assets in the region.

\section{LITERATURE REVIEW}

In recent years, the mathematical programming model algorithm of agricultural machinery allocation has become more and more mature. Tiotsop et al. (2020) combined with the actual data and information of the farm, and based on the mathematical planning model, obtained the optimal agricultural machinery usage. Richárd et al. (2019) made a comprehensive study on agricultural machinery allocation by using the mathematical programming model. But the mathematical programming model of agricultural machinery is not combined with weather factors, so it is easy to have problems in the operation process. Bäuerle et al. (2019) studied the allocation of agricultural machinery in combination with weather factors, and analyzed the production process of some crops by using the mathematical programming model of agricultural machinery allocation. Lancia et al. (2018) Made use of the mathematical planning model of agricultural machinery allocation, and established the objective function and workload of minimum cost according to the demand of agricultural machinery in different regions. Hussein et al. (2019) presents a study which found that the mathematical planning model of agricultural machinery allocation has good feasibility and practicability, which can be used to solve the problem of agricultural machinery allocation in the whole production field and promote the development of agriculture in China. For a long time, the mathematical programming model of agricultural machinery equipment has been an important topic in academic research. Through the comparison of various solutions, it is found that linear programming is feasible, but it is not 
the most effective method. In recent years, Qiang et al. (2018); Zenghui et al. (2018) the academic community has been studying a new algorithm, namely decomposition coordination algorithm. Firstly, the large-scale system is decomposed into several relatively independent subsystems, and then a coordinator is set up for each subsystem, which is mainly used to deal with the correlation between subsystems, and then the corresponding optimal solution is obtained through continuous coordination. Decomposition and coordination algorithm has certain requirements, so it limits its scope of application to a certain extent.

In farming framework crop plan choices are very significant. Subsequently, a knowledge based methodology is adopted to define an incorporated farm management system. Such an incorporated farm situation gives a knowledge to determine the excess of the boundaries with the end goal that it gets adjusted dependent on the accessibility and convenience of assets in an area.

Alongside these parameters, the agribusiness area is influenced by shifting climatic conditions and limited accessibility of water assets as well. An examination had been completed by Kuntashula et al. (2014) to decide the impact of crop rotation adaption. It is seen that even a short-rotations, for example, maize-soybeans will give a rotational impact and will impact crop efficiency. The investigation infers that more often than not crop yield is more when developed in turn when contrasted with that when developed as a continuous crop in a season.

Improving the irrigation network and apportioning resources of water and arable land are two most significant boundaries for management of farms. The distribution of water assets is very prescient as it relies upon the water prerequisite of the cultivated crop. Consequently, Li et al. (2017) proposed a model with the objective to augment all benefits from farm by ideally dispensing available water assets over an arranging horizon. Results show that a Linear Programming approach is a successful instrument for channelizing irrigation in farm land. Breidenbach et al. (2016) proposed a multistage water irrigation scheme to determine and finding the solution of vulnerabilities associated within it. Fluctuating accessibility of water assets and its demand, variety in crop return and economic benefits joined by the adjustment in the water irrigation system design regularly challenge the leaders in each developing season. These issues become more perplexing because of an expansion in food interest and a decrease in the openness of assets. Subsequently, multistage Stochastic Programming is utilized to handle the convexity of choice variables. However, such a methodology makes the situation more reasonable as it incorporates the probabilistic methodology as well.

In this paper, based on the constraint equation, aiming at the mathematical planning model of agricultural machinery allocation, the constraint equation is first used to solve the problems in the planning, so as to obtain the overall optimal solution, and finally combined with computer simulation. The speed of this algorithm is five times higher than that of other algorithms.

\section{EXPERIMENTAL METHODS}

In the calculation process of agricultural machinery allocation, all constraint equations can be independent by eliminating the independent constraint equations. Before establishing the constraint equation of agricultural machinery allocation, it is necessary to collect relevant information from the operating units. Usually, the information collected includes the operation items, time and the number of farm tools in the same stage. Kollas et al. (2015); Conrad et al. (2016) studied crop rotationthrough the calculation of constraint equation and objective function, the problem was automatically generated and solved, which laid the foundation for the mathematical planning model of agricultural machinery.

\subsection{Linear Programming Method}

Linear programming models generally need to involve the number of agricultural machinery equipped and the number of classes that agricultural machinery needs to complete. 


\subsubsection{Establish the Constraint Equation of the Amount of Agricultural Tools}

Before establishing the constraint equation of the amount of agricultural tools, it is necessary to collect the relevant information of the operating units. Usually, the information collected includes the operation items, time and the number of farm tools in the same stage. Because there may be some cross operations in the process of agricultural tools allocation, and the operations are independent of each other, in order to avoid the situation that one machine occupies the whole time, the power and operation days of agricultural machinery should be combined when establishing the constraint equation of agricultural tools allocation Yuvaraj et al. (2015). In addition, for the power machinery equipped with agricultural machinery and the working time of agricultural machinery equipment consumes the same amount of machinery, that is, the tractor consumes 1 hour of agricultural machinery equipment at the same time. Because the Corps belongs to the temperate continental climate, the annual drought and less rain, the efficiency of agricultural machinery allocation is less affected by rainfall, and the probability of agricultural machinery equipment can be completed in the ground is taken as 0.9 . In the process of establishing the constraint equation of the amount of agricultural tools, combined with the operation items, agricultural machinery and working time, and according to the actual situation and distribution network diagram, the dynamic constraint equation is established as follows:

$$
\sum_{i=1} \sum_{k=1} X_{i j k} \leq Y_{j} \quad(j=1,2,3, \cdots)
$$

In the formula, xijk represents the operation time $(\mathrm{H})$ of matching $\mathrm{K}$ agricultural machinery corresponding to J-type tractor during the implementation of operation I, and YJ represents the hours consumed in the whole working process $(\mathrm{H})$. The working time of type I tractor required in the dynamic constraint equation is no longer than the total mechanical running time.

The constraint equation of agricultural machinery was established as follows:

$$
\sum_{i=1} \sum_{j=1} X_{i j k} \leq Z_{k} \quad(k=1,2,3, \cdots)
$$

In the formula, $\mathrm{ZK}$ represents the total machine hours $(\mathrm{H})$ used in the working process of K-type agricultural machinery. The constraint equation of agricultural machinery needs to ensure that the working time of all K-type agricultural machinery is no longer than the total machine running time.

The established workload constraints are as follows:

$$
\sum_{j=1} \sum_{k=1} W_{i j k} X_{i j k}=A_{i} \quad(i=1,2,3, \cdots)
$$

In the formula, Wijk represents the productivity (hm22h) of K-type agricultural machinery equipped when the J-type tractor corresponding to operation I works; AI refers to the operating area (hm2) of I-type agricultural machinery allocation operation. The constraint equation of work volume represents that the sum of the corresponding operation area of agricultural tools is equal to the total area of corresponding project operation.

\subsubsection{Establish Objective Function}

The determination of the objective function needs to be combined with the corresponding unit requirements of agricultural machinery. Usually, it needs to meet the conditions of low cost and high efficiency. For the cost of agricultural machinery, including energy costs, wages and maintenance costs, the mathematical programming model needs to take the minimum cost as the objective function 
[12]. In general, the variable cost will change with the amount of work. The constraint equation of objective function is established as follows:

$S_{\min }=B_{j k} X_{i j k}+C_{j k} W_{i j k} X_{i j k}$

\subsubsection{Software Solution}

In this paper, we need to use more variables to build the mathematical programming model, so we need to rely on lingo software to solve. The software belongs to interactive linear general optimization solver, which has strong processing capacity, high efficiency and simple operation, and is widely used in linear programming analysis.

\subsection{Workload Method}

Generally, for the agricultural machinery which has completed a certain operation and has been equipped, the corresponding allocation model is established by combining the workload method as follows:

$n_{r m}=\frac{U_{r m}}{D_{r m} \alpha_{r m} W_{r m}}$

In the formula, $\mathrm{R}$ is the serial number of machinery; NRM is the specific number of agricultural machinery required to complete the R operation, unit: set; URM is the specific area required to complete the $\mathrm{R}$ operation, unit: $\mathrm{Mu}$; DRM is the specific days required to complete the $\mathrm{R}$ operation, unit: day; arm is the specific shift required to complete the R operation, unit: machine shift; WRM is the productivity of each shift required to complete the R operation Unit: \%.

\section{EXPERIMENTAL RESULTS}

As an effective method to study the allocation of agricultural machinery, mathematical programming model needs to comprehensively consider the external factors such as operation time, workload and machine productivity. Only after comprehensive consideration can we get a satisfactory allocation result. The investigation shows that the cultivated land area of BINGTUAN studied in this paper is more than 8000 hectares, of which cotton planting area is more than 4000 hectares, wheat planting area is 1300 hectares, and tomato planting area is 600 hectares. According to the actual planting requirements and characteristics of XPCC, combined with other information obtained, the model has a positive effect on the analysis results (Tables 1-3).

As a result of the shortage of agricultural machinery, the production cost of cotton will be increased to a certain extent. In this paper, five planting schemes are determined. Table 3 is the planting scale corresponding to various crops in the five schemes. Combined with the mathematical linear programming model, the agricultural machinery allocation model is established, and each crop corresponds to a kind of agricultural machinery allocation scheme. Then the software is used to compare the various planting scales of the corps and select the optimal scheme.

According to Table 4, the activity cost of scheme 1 is the highest and that of scheme 5 is the lowest. At present, the cotton field operation of the Corps has been basically mechanized. Therefore, the plan to terminate the expansion of cotton scale has higher operation cost. It is found that with the decrease of cotton planting scale in XPCC, the number of Dongfanghong 1x2204 tractor in power machinery will increase, and the number of other tractors will decrease accordingly, among which the largest reduction is Foton $\operatorname{tg} 1654$ tractor. When the cotton planting scale is reduced, the number 
Table 1. Annual mechanized operation process of main crops

\begin{tabular}{|c|c|c|c|c|c|c|c|c|c|}
\hline \multirow[b]{2}{*}{$\begin{array}{c}\text { Serial } \\
\text { number }\end{array}$} & \multirow[b]{2}{*}{ Work items } & \multicolumn{2}{|c|}{ Timely operation period } & \multirow{2}{*}{$\begin{array}{c}\text { Task } \\
\begin{array}{c}\text { The } \\
\text { measure } \\
\text { of area } \\
\text { (MU) }\end{array}\end{array}$} & \multicolumn{4}{|c|}{ Unit shift productivity (mu shift) } & \multirow{2}{*}{$\begin{array}{c}\text { Daily work } \\
\begin{array}{c}\text { Number of } \\
\text { shifts }\end{array}\end{array}$} \\
\hline & & $\begin{array}{l}\text { Start and } \\
\text { end date }\end{array}$ & $\begin{array}{l}\text { Working } \\
\text { days }\end{array}$ & & $\begin{array}{c}\text { Futian } \\
\text { TG1654 }\end{array}$ & $\begin{array}{c}\text { Oriental } \\
\text { red } \\
\text { LX2204 }\end{array}$ & $\begin{array}{c}\text { John } \\
\text { Deere } \\
\text { JD5-750 }\end{array}$ & $\begin{array}{c}\text { Oriental red } \\
\text { LX754 }\end{array}$ & \\
\hline 1 & $\begin{array}{l}\text { Elimination } \\
\text { of Tomato }\end{array}$ & $3.22-4.05$ & 9 & A3 & - & - & 400 & 400 & 1 \\
\hline 2 & $\begin{array}{l}\text { Whole } \\
\text { tomato field }\end{array}$ & $4.02-4.08$ & 7 & $\mathrm{~A} 3$ & 210 & 250 & - & - & 2 \\
\hline 3 & $\begin{array}{l}\text { Cotton } \\
\text { removal }\end{array}$ & 4.03-3.09 & 7 & A1 & - & - & 400 & 400 & 1 \\
\hline$\ldots$ & $\ldots$ & $\ldots$ & $\ldots$ & $\ldots$ & $\ldots$ & $\ldots$ & $\ldots$ & $\ldots$ & $\ldots$ \\
\hline 9 & Cotton pole & $\begin{array}{l}10.22- \\
10.30\end{array}$ & 8 & A1 & - & - & 200 & 200 & 2 \\
\hline 10 & Cotton fields & $\begin{array}{l}10.22- \\
10.30\end{array}$ & 8 & $\mathrm{~A} 1$ & 110 & 150 & - & - & 2 \\
\hline
\end{tabular}

Table 2. Fixed cost of agricultural machinery

\begin{tabular}{|l|l|l|l|l|l|}
\hline $\begin{array}{c}\text { Name of } \\
\text { agricultural } \\
\text { machinery }\end{array}$ & Foton tg1654 & $\begin{array}{c}\text { Dongfanghong } \\
\mathbf{l x 2 2 0 4}\end{array}$ & $\ldots \ldots .$. & Baled straw & $\begin{array}{c}\text { Straw returning } \\
\text { machine }\end{array}$ \\
\hline Price (yuan) & 390000 & 516000 & $\ldots \ldots$ & 50000 & 5000 \\
\hline $\begin{array}{l}\text { Annual fixed } \\
\text { expenses (yuan) }\end{array}$ & 63500 & 84270 & $\ldots \ldots$ & 50000 & 1700 \\
\hline
\end{tabular}

Table 3. Planting scale of XPCC (area: HM2)

\begin{tabular}{|l|l|l|l|}
\hline \multicolumn{1}{|c|}{ Programme } & \multicolumn{1}{|c|}{ Cotton (A1) } & \multicolumn{1}{c|}{ Wheat (A2) } & \multicolumn{1}{c|}{ Tomato (A3) } \\
\hline Scheme 1 & 5500 & 2000 & 600 \\
\hline Scheme 2 & 5500 & 1200 & 1200 \\
\hline Scheme 3 & 4800 & 2600 & 600 \\
\hline Scheme 4 & 4800 & 2000 & 1200 \\
\hline Scheme 5 & 4100 & 2600 & 1200 \\
\hline
\end{tabular}

Table 4. Activity cost of Scale Allocation

\begin{tabular}{|l|l|l|l|l|}
\hline Scheme 1 & \multicolumn{1}{|c|}{ Scheme 2 } & \multicolumn{1}{c|}{ Scheme 3 } & \multicolumn{1}{c|}{ Scheme 4 } & \multicolumn{1}{c|}{ Scheme 5 } \\
\hline 1380 & 1393 & 1313 & 1328 & 1260 \\
\hline
\end{tabular}

of cotton machinery will be reduced, and the number of tomato and wheat machinery will increase, among which the wheat harvester has the largest change.

According to Figure 1, with the decrease of cotton planting scale, the number of sprayers decreased steadily, while the number of four ploughs increased first and then decreased, the number 
Figure 1. Change trend of agricultural machinery quantity

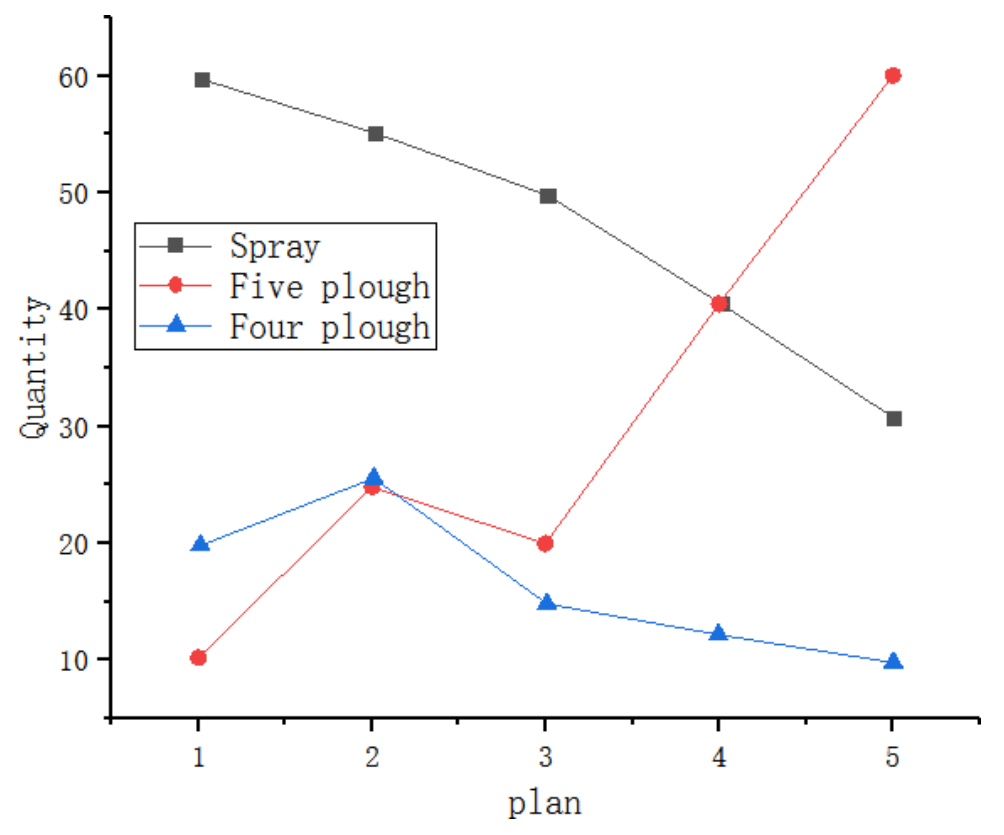

of five share ploughs increased at the beginning of the period, and then increased again after a small reduction. The number of other agricultural machinery showed an increasing trend, and the change range of each agricultural machinery quantity was larger.

By solving the multi-target model with stretch parameters by the considered referenced intelligent algorithm, a sensible result vector can be acquired.

In this examination, the threshold value $\alpha_{i}$ that varies simultaneously at the same time to find the solution of the model without any problem. $f_{1}^{c}(x), f_{2}^{c}(x)$ and the value of $f_{3}^{c}(x)$ are the objective estimation of target work of the net advantage of economy, measure of sewage waste and greenbelt water irrigation system zone, respectively. For the year of 2010, when $\epsilon=0.9$, after the computation, three considered objective values of $f_{1}^{c}(x), f_{2}^{c}(x)$ and $f_{3}^{c}(x)$ are 1,58,34,876, 34,427.78 and 86.32 which are presented in Table 4. Consequently, the solution is $x=[14523.48,14356.85,6893.45$, $32369.35,1328.39,726.35]$. These solutions are compared with the result present in Yue et al. (2020), the solutions in this investigation can likewise flexibly connection among multi-objectives as tabulated in Table 5 other than providing comparable information which can be given by Zhang et al. (2018).

Similarly, the results multiple source water irrigation system under various thresholds values are presented in Table 6 .

As indicated by Table 6 , with expanding of threshold value $(\alpha)$, the requirement is fixed which implies accessible water decreases, framework risk will reduce. The best quality of water for industry reduces from 158.243 to 143.293 million cubic meters, anyway the reused water for industry increments from 132.352 to 146.582 million cubic meters; the decrement of high quality water utilization is practically equivalent to the expansion of reused water for industry, suggesting that the aggregate sum of water utilization in industry isn't delicate to the satisfaction threshold value $(\alpha)$. The high quality water for agribusiness increments from 63.253 to 70.253 million cubic meters, while the agriculture in city isn't the essential water consumption area.

As per the demand of comparatively stable population and per capita water requirement the reported change in the consumption of water domestically is small which 0.3 percent of improvement 
Table 5. Variation of three objective values for different values of $\varepsilon\left(\alpha_{i}=0.8\right)$

\begin{tabular}{|l|l|l|l|}
\hline \multicolumn{1}{|c|}{$\varepsilon$} & \multicolumn{1}{|c|}{$f_{1}^{c}(x)$} & \multicolumn{1}{c|}{$f_{2}^{c}(x)$} & \multicolumn{1}{c|}{$f_{3}^{c}(x)$} \\
\hline 0 & 93,458 & $12,658.98$ & 1057.85 \\
\hline 0.1 & $17,69,427$ & $15,567.34$ & 968.24 \\
\hline 0.2 & $35,47,241$ & $17,423.56$ & 853.17 \\
\hline 3 & $52,36,472$ & $20,349.90$ & 756.38 \\
\hline 0.4 & $62,37,875$ & $22,451.74$ & 698.57 \\
\hline 0.5 & $84,53,769$ & $24,578.81$ & 547.28 \\
\hline 0.6 & $1,04,36,871$ & $27,523.65$ & 425.37 \\
\hline 0.7 & $1,26,51,786$ & $30,231.67$ & 300.68 \\
\hline 0.8 & $1,39,80,754$ & $32,459.45$ & 196.35 \\
\hline 0.9 & $1,58,34,876$ & $34,427.78$ & 86.32 \\
\hline 1 & $1,73,78,812$ & $37,346.43$ & 29.15 \\
\hline
\end{tabular}

Table 6. Results multiple source water irrigation system under various thresholds values

\begin{tabular}{|l|l|l|l|l|l|l|}
\hline $\boldsymbol{\alpha}$ & $\begin{array}{c}\text { High quality } \\
\text { water for } \\
\text { industry }\end{array}$ & $\begin{array}{c}\text { Reused } \\
\text { water for } \\
\text { industry }\end{array}$ & $\begin{array}{c}\text { High quality } \\
\text { water for } \\
\text { agriculture }\end{array}$ & $\begin{array}{c}\text { High quality } \\
\text { water for } \\
\text { domestic }\end{array}$ & $\begin{array}{c}\text { High quality } \\
\text { water for } \\
\text { greenbelt }\end{array}$ & $\begin{array}{c}\text { Reused } \\
\text { water for } \\
\text { greenbelt }\end{array}$ \\
\hline 0 & 15824.36 & 13235.23 & 6325.35 & 32254.32 & 4365.32 & 1847.32 \\
\hline 0.2 & 15632.28 & 13465.36 & 6547.2 & 32268.29 & 3651.28 & 1542.36 \\
\hline 0.4 & 15329.3 & 13579.2 & 6685 & 32357.63 & 2687.2 & 1327.66 \\
\hline 0.6 & 14657.26 & 13756.67 & 6723.63 & 32374.15 & 2354.16 & 1029.31 \\
\hline 0.8 & 14523.48 & 14356.85 & 6893.45 & 32369.35 & 1328.39 & 726.35 \\
\hline 1 & 14329.36 & 14658.27 & 7025.31 & 32380.24 & 724.9 & 535.82 \\
\hline
\end{tabular}

from 32.254 to 38.380 in million cubic meters. Additionally, considering the effects of rainfall, humidity and evaporation there exists some nondeterministic functions which effects the water requirement of greenbelt irrigation. This further results as a change in the consumption of water for the greenbelt irrigation with the decrement in demand of water to the farm along with the increment in threshold value. Figure 2 represents the variation in multiple resource allocation of water irrigation system for different threshold values. It is observed from the experiments that the overall economic profit along with the sewage cost increases. It is also observed that the irrigation system for greenbelt zone decreases with the increment in threshold value. The threshold value represents as an indicator for the trade-off among the profits from system and the risks involved.

The allocation of different water assets are a fuzzy interval and not a deterministic term. This infers that the allocation of multiple source resource of water is reliable with the fuzzy attribute of water supply and request, which too demonstrates a certifiable allocation of water resources under 
Figure 2. Variation of multiple source allocation of water with threshold

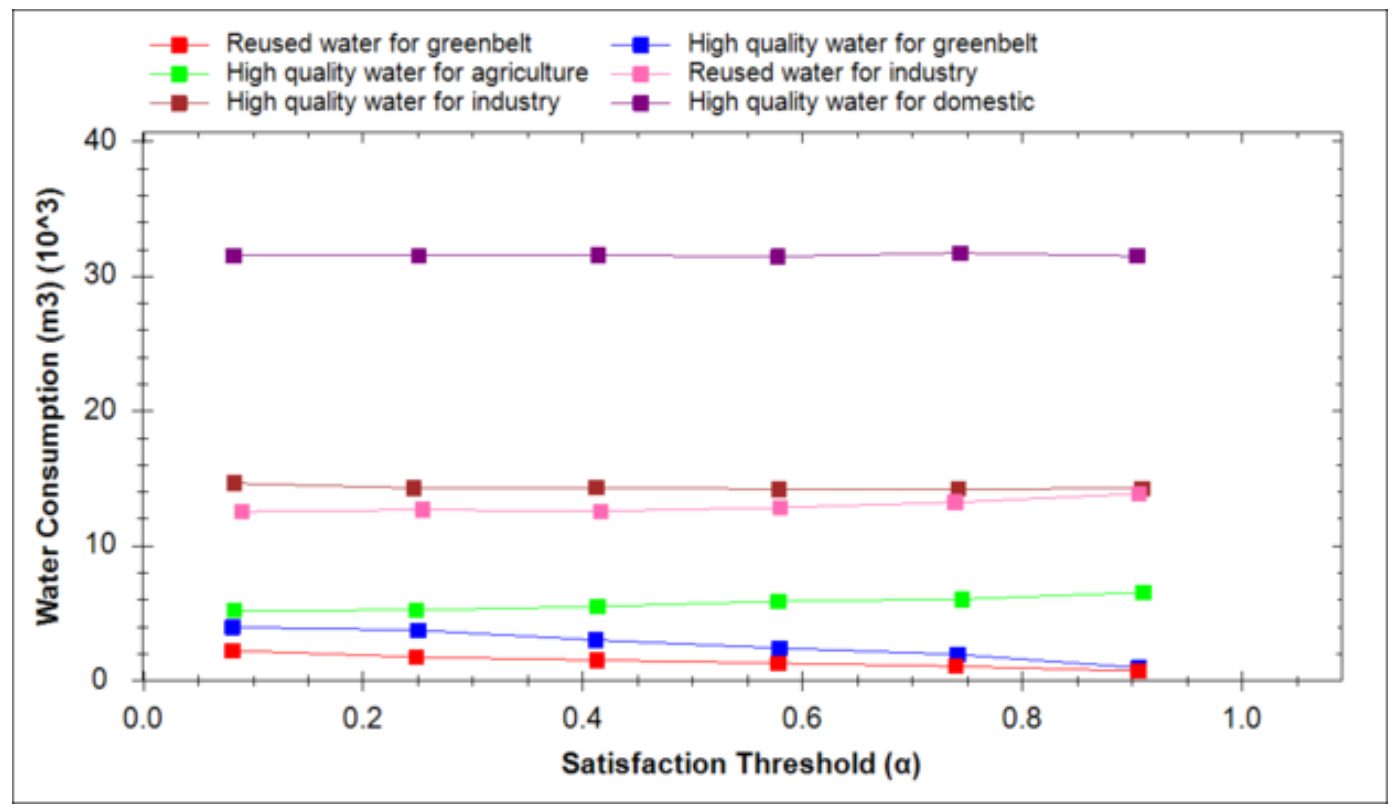

vulnerability. Figure 3 presents the aftereffects of designation of multiple source resource of water assets for different clients under interval vulnerability in 2010.

Figure 4 represents the allocation of multiple resource of water irrigation system for multiple clients during year 2010, 2015 and 2020. It is observed that the overall consumption of water will increase upto 724.92 million cubic meter by the year 2020. It is also observed that the portion of consumption of reused water in comparison with the overall water consumption will increase from $18.26 \%$ in year 2010 to $20.62 \%$ in year 2015 and to $22.14 \%$ in year 2020 . In view of lower advantage of consumption of agriculture water, the consumption will be slice down step by step to accomplish an ideal overall advantage of water resources management. The outcomes of the proposed framework

Figure 3. Outcomes of allocation of multiple resource under vulnerability in $\mathbf{2 0 1 0}$

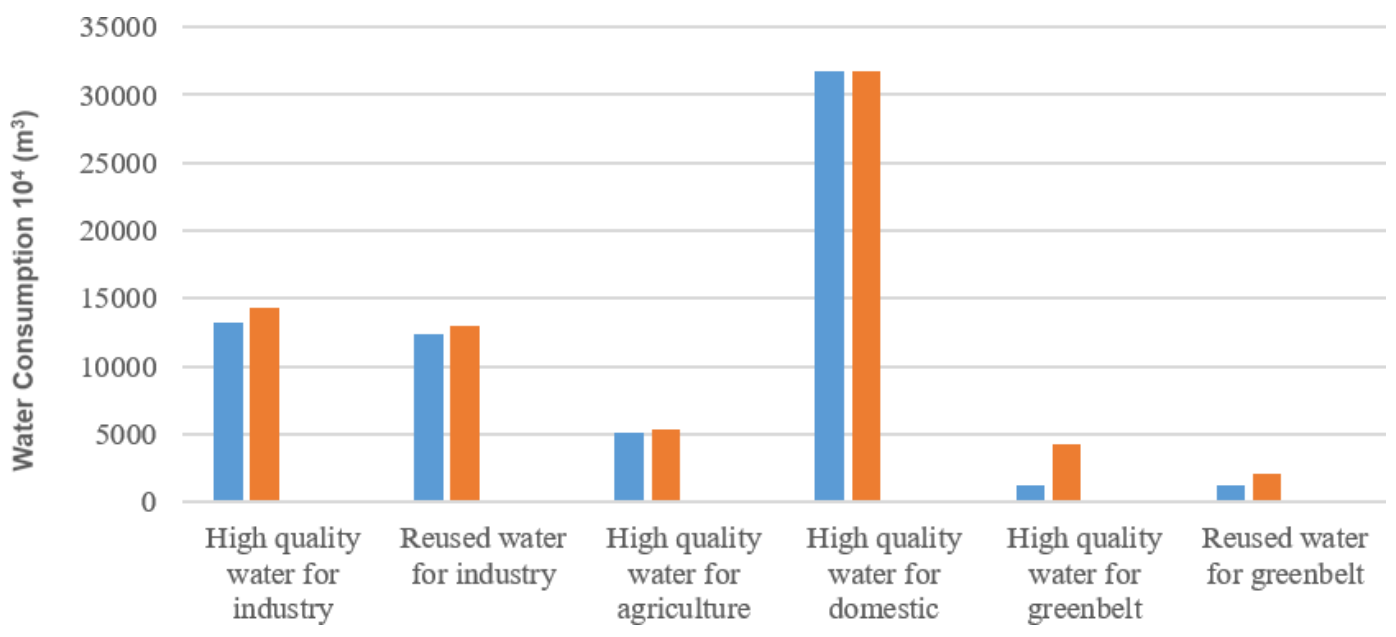


Figure 4. The allocation of multiple source water for various clients in different years

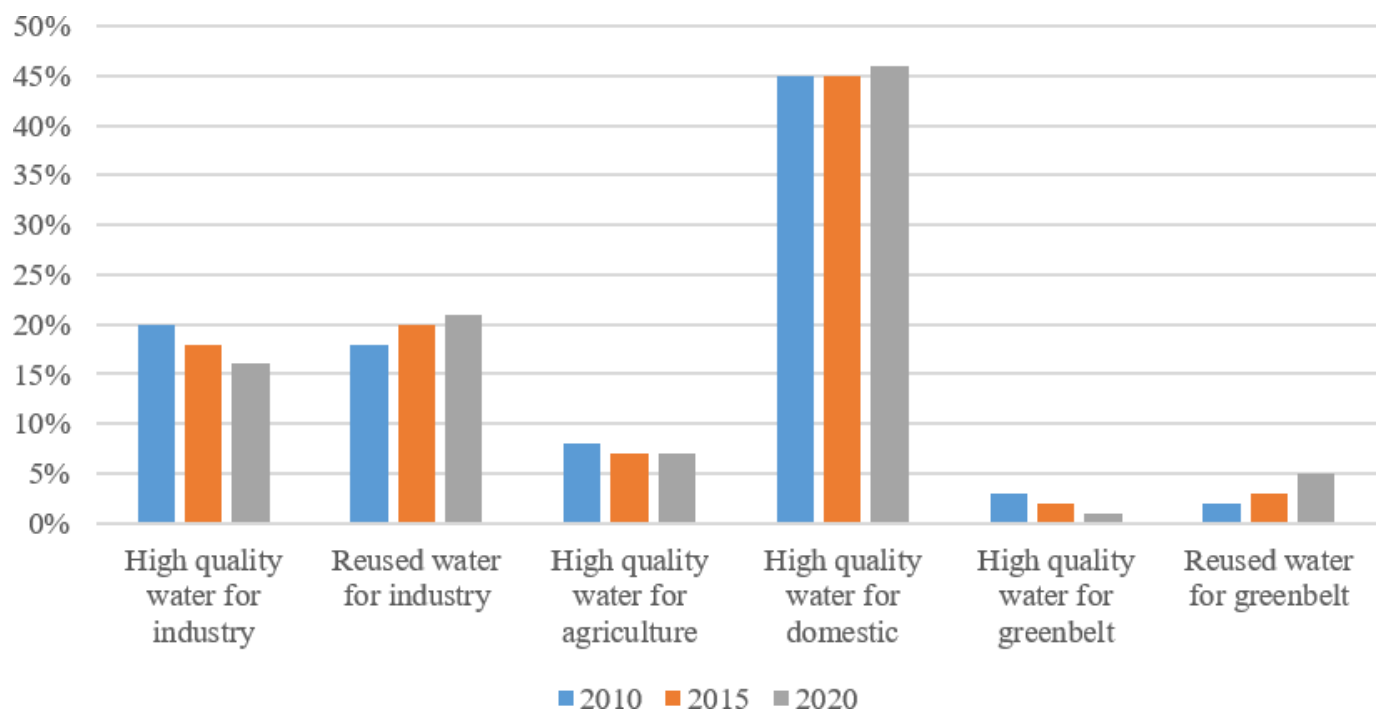

demonstrates that the resources of reused water will be paid more consideration for sparing the high quality water cities later on.

\section{CONCLUSION}

In terms of activity-based cost, cotton has basically realized the whole process of mechanization, reducing a large number of labor, but the high degree of mechanization means the need for higher machinery operation cost. With the rapid development of science and technology, mechanized operation has become an important development trend. The mathematical planning model needs to be combined with the specific situation of agricultural machinery operation, and the objective function and equation are manually edited and analyzed. The workload is large, and errors are prone to occur in the whole process. Secondly, if the number of the whole project is large, it is easy to cross each other. In addition, the number of corresponding equations is large, which will lead to the lack of memory in the microcomputer of relevant management departments and the need to rely on external hardware equipment, Increase the operation time. The above problems have great influence on the process of mathematical planning model of agricultural machinery allocation. In general, for different species of planting scale of agricultural machinery, we need to compare each configuration scheme, and use software to solve all the models to improve the overall operation efficiency and get the best agricultural machinery allocation scheme. Only when a reasonable agricultural machinery allocation scheme is realized can the maximum benefit be obtained. Advanced technology improves the overall operational efficiency of the mathematical planning and analysis process. After solving the problem of automatic generation of constraint equation and objective function, the foundation of mathematical programming model of agricultural machinery equipment is established. 


\section{REFERENCES}

Bäuerle, N., \& Schmithals, D. (2019). Martingale optimal transport in the discrete case via simple linear programming techniques. Mathematical Methods of Operations Research, 90(3), 453-476. doi:10.1007/s00186019-00684-8

Breidenbach, B., Blaser, M. B., Klose, M., \& Conrad, R. (2016). Crop rotation of flooded rice with upland maize impacts the resident and active methanogenic microbial community. Environmental Microbiology, 18(9), 2868-2885. doi:10.1111/1462-2920.13041 PMID:26337675

Conrad, C., Lamers, J. P. A., Ibragimov, N., Löw, F., \& Martius, C. (2016). Analysing irrigated crop rotation patterns in arid Uzbekistan by the means of remote sensing: A case study on post-Soviet agricultural land use. Journal of Arid Environments, 124, 150-159. doi:10.1016/j.jaridenv.2015.08.008

Galán-Martín, Á., Pozo, C., Guillén-Gosálbez, G., Vallejo, A. A., \& Esteller, L. J. (2015). Multi-stage linear programming model for optimizing cropping plan decisions under the new Common Agricultural Policy. Land Use Policy, 48, 515-524. doi:10.1016/j.landusepol.2015.06.022

Hussein, A. S., Elias, C. M., \& Morgan, E. I. (2019). A Realistic Model Predictive Control using Single and Multiple Shooting in the Formulation of Non-linear Programming Model. In 2019 IEEE International Conference on Vehicular Electronics and Safety (ICVES). IEEE. doi:10.1109/ICVES.2019.8906364

Kollas, C., Kersebaum, K. C., Nendel, C., Manevski, K., Müller, C., Palosuo, T., \& Conradt, T. (2015). Crop rotation modelling-A European model intercomparison. European Journal of Agronomy, 70, 98-111. doi:10.1016/j.eja.2015.06.007

Kuntashula, E., Chabala, L. M., \& Mulenga, B. P. (2014). Impact of minimum tillage and crop rotation as climate change adaptation strategies on farmer welfare in smallholder farming systems of Zambia. Journal of Sustainable Development, 7(4), 95. doi:10.5539/jsd.v7n4p95

Lancia, G., \& Serafini, P. (2018). Compact extended linear programming models. Polyhedra. doi:10.1007/9783-319-63976-5

Lanfranchi, M., Giannetto, C., Abbate, T., \& Dimitrova, V. (2015). Agriculture and the social farm: Expression of the multifunctional model of agriculture as a solution to the economic crisis in rural areas. Bulgarian Journal of Agricultural Science, 21(4), 711-718.

Lang-Ni, D., Ri-Sheng, L., Liang, G., Jin-Chao, M. A., \& Xiao-Xia, H. (2018). Earthwork allocation based on mathematical model algorithm of linear programming. Journal of Civil Engineering and Management.

Li, T., Long, H., Zhang, Y., Tu, S., Ge, D., Li, Y., \& Hu, B. (2017). Analysis of the spatial mismatch of grain production and farmland resources in China based on the potential crop rotation system. Land Use Policy, 60, 26-36. doi:10.1016/j.landusepol.2016.10.013

Molnár-Szipai, R., \& Varga, A. (2019). Integrating combinatorial algorithms into a linear programming solver. Central European Journal of Operations Research, 27(2), 475-482. doi:10.1007/s10100-018-0552-9

Prišenk, J., Turk, J., Rozman, Č., Borec, A., Zrakić, M., \& Pažek, K. (2014). Advantages of combining linear programming and weighted goal programming for agriculture application. Operations Research, 14(2), $253-260$. doi:10.1007/s12351-014-0159-4

Qiang, Y., Caixia, G., Bin, L. V., \& Chao, S. U. (2018). Design of agricultural machinery scheduling algorithm based on $3 s$. Agriculture Network Information.

Tiechuang, Z., Wenjing, X., \& Amp, L. V. (2018). Research on numerical control machining and forming technology of complex parts of agricultural machinery. Nong-ji-hua Yanjiu.

Tiotsop, L. F., Servetti, A., \& Masala, E., (2020). An integer linear programming model for efficient scheduling of UGV tasks in precision agriculture under human supervision. Computers \& Operations Research, 114, 104826.1-104826.11.

Yue, Q., Wang, Y., Liu, L., Niu, J., Guo, P., \& Li, P. (2020). Type-2 fuzzy mixed-integer bi-level programming approach for multi-source multi-user water allocation under future climate change. Journal of Hydrology (Amsterdam), 591, 125332. doi:10.1016/j.jhydrol.2020.125332 
Yuvaraj, D., Karthik, R., \& Muthezhilan, R. (2015). Crop rotation as a better sanitary practice for the sustainable management of Litopenaeus vannamei culture. Asian Journal of Crop Science, 7(3), 219-232. doi:10.3923/ ajcs.2015.219.232

Zenghui \& Zhao. (2018). Research on Mixed Mode Teaching of C Language Programming. Academic Press.

Zhang, S., Yang, J., Wan, Z., \& Yi, Y. (2018). Multi-water source joint scheduling model using a refined water supply network: Case study of Tianjin. Water (Basel), 10(11), 1580. doi:10.3390/w10111580

Xiaoling Zhou is with Basic Course Department, Guangzhou Railway Polytechnic in China.

Vandana Mohindru $(P h D)$ received her Ph.D. in CSE from Jaypee University of Information Technology, Waknaghat, H.P., India. She is working as an Assistant Professor in the Department of Computer Science and Engineering, Chandigarh Group of Colleges - College of Engineering, Mohali, Punjab, India since 2017. Dr. Vandana is a renowned researcher in the areas of Internet of Things, Wireless Sensor Networks, Security, Blockchain and Cryptography, Unmanned Aerial Vehicles. She has published more than 20 technical research papers in leading journals and conferences from IEEE, Elsevier, Springer, etc. She organized International Conferences and chaired various sessions during the IEEE \& Springer conferences. 